\title{
Land Seismic Multiples Detection and Attenuation In Bornu-Chad Basin, Nigeria
}

\section{Dorathy B. Umoetok ${ }^{a *}$, Etim D. Uko ${ }^{b}$, Iyeneomie Tamunobereton-ari, Chigozie Israel-Cookey ${ }^{\mathrm{b}}$, Odukokoma N. Ebinia}

a Integrated Data Sciences Limited, Nigerian National Petroleum Corporation (NNPC), Benin City, Nigeria.

b Department of Physics, Rivers State University, PMB 5080, Port Harcourt, Nigeria.

*Corresponding Author email: umoetok.dorathy@nnpc-idsl.com; e_uko@yahoo.com

\section{DOI: $10.2478 / p j g-2020-0009$}

\section{Abstract:}

Three dimensional (3D) seismic survey was acquired and processed in Bornu-Chad basin, Nigeria with the aim of detecting and attenuating multiples to aid proper imaging of the subsurface. The $25.5 \mathrm{~km} 2$ volume was processed using SeisUp processing software on a 32 -Node Cluster Infrastructure (CI) hardware. Considering the imaging objectives and depth of interest of $1.2 \mathrm{~s}-4.5 \mathrm{~s}$, the minimum, middle and maximum offsets were set at $500-2300 \mathrm{~m}, 2500-$ $4300 \mathrm{~m}$ and $4500-7300 \mathrm{~m}$ respectively. Since the study area comprised of dry open land and swampy Lake Chad, vibroseis and dynamite sources were used respectively. Charge depth was $0 \mathrm{~m}$ (surface) for vibroseis and $25 \mathrm{~m}$ dynamite. The dataset was first pre-conditioned, normalized, regularized before application of demultiple process. The detection and demultiple processes based on multiple characteristics of periodicity and velocity discrimination were applied as the multiples have comparable velocity with the primaries. The near-surface reverberations and short-period multiples were attenuated using predictive deconvolution and radon transform algorithms. High resolution radon was performed on post-migrated common-mid-point (CMP) gathers and stacked with $1 \mathrm{~km} \times 1 \mathrm{~km}$ target line velocities. Internal multiples were detected and attenuated using data-driven methodology of extended internal multiple prediction (XIMP). Multiples detected were short, long period and interbed multiples on all frequencies ranges of $0-90 \mathrm{~Hz}$ but useful seismic frequency range was between $20 \mathrm{~Hz}$ and $70 \mathrm{~Hz}$. The frequencies and amplitudes of the primaries and multiples were very comparable, therefore great care was taken in the attenuation processes. The results of this work has produced better seismic section for interpretation of subsurface geology in the study area.

Keywords: seismic; multiple; amplitudes; detection; attenuation; Bornu-Chad Basin, Nigeria.

\subsection{Introduction:}

A Multiple reflection is a seismic energy which is reflected at more than one interface [1 - 13]. A primary reflection is an event that is considered to be the seismic signal. Primaries experience one upward reflection and no downward reflections. The direct wave travels horizontally from the source to receivers without hitting any reflector. A multiple is a recorded event that can be decomposed into a number of other events that appear within the same data set. Multiple reflection results from the difference in impedance across layers (Figure 1).

Multiples are problems for both land and marine seismic acquisitions. They are not easy to discriminate from primary reflections in land data. On land, multiples usually lack the familiar periodicity accompanying marine multiples [1,14-18]. The problem to address on land is to prove that multiples exists [13] Most of the technical literatures on multiple detection and attenuation are mostly for multiple reflections in the marine environment [19, 20, 20]. George-Best [21] observed that Agbada Formation is the multiple-generators in the onshore (land) Niger Delta. He failed to validate his method with other algorithms.

Since multiples are undesirable, a large variety of methods has been developed to detect, predict and attenuate them since late 1940s based on the properties of multiples [22, 23]. The first property of primaries is that multiples tend to have more moveout than primaries [24, 25, 26, 27]. Secondly, multiples have more curvature than primaries $[28,29,25,30,31]$. This is because multiples have longer arrival-times than primaries. The third property of multiples that forms the basis of suppression is periodicity [32, 24, 33]. Many orders of multiples could be generated in a seismic experiment, whereas primaries only arrive once from each reflector. As a result, multiples tend to be periodic whereas primaries are not [24, 34, 35, 36]. In this Paper, 3D land seismic data is processed to detect and attenuate multiple reflections.

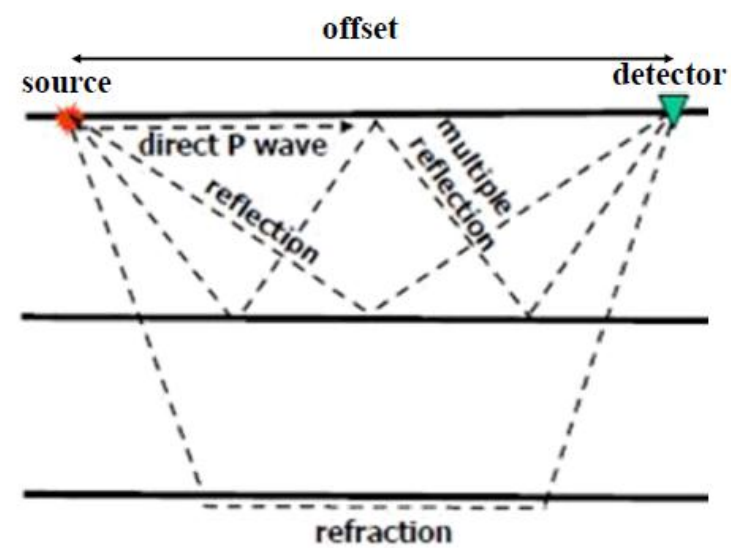

Figure 1: Example of Refraction, Primary and Multiple Reflections

\subsection{Area of Study}

The Chad basin is situated in N-E Nigeria. The basin extends to the Republic of Niger, Chad, Sudan and the northern Cameroon and Nigeria within latitudes $10^{\circ} \mathrm{N}$ to $14^{\circ} \mathrm{N}$ and longitudes $12^{\circ} \mathrm{E}$ to $15^{\circ} \mathrm{E}$ (Figure 2). The Bornu basin is in Nigeria with latitudes $11^{\circ} \mathrm{N}$ and $14^{\circ} \mathrm{N}$ and longitudes $9^{\circ} \mathrm{E}$ and $14^{\circ} \mathrm{E}$. The $\mathrm{Nigerian}$ Chad Basin is one inland basins. It occupies the north-eastern part of Nigeria. It shares boundaries with Bornu State, Jigawa and Yobe States [37, 38]. It belongs to the West Central African Rift System (WCAS) [39]. The basin occupies one-tenth of Lake Chad (Figure 2). It is the largest inland basin in Africa. Its geographical surface area is approximately $2,500,000 \mathrm{~km}^{2}$. Its elevation is $300 \mathrm{~m}$ within Lake Chad and about $530 \mathrm{~m}[37,38]$. 


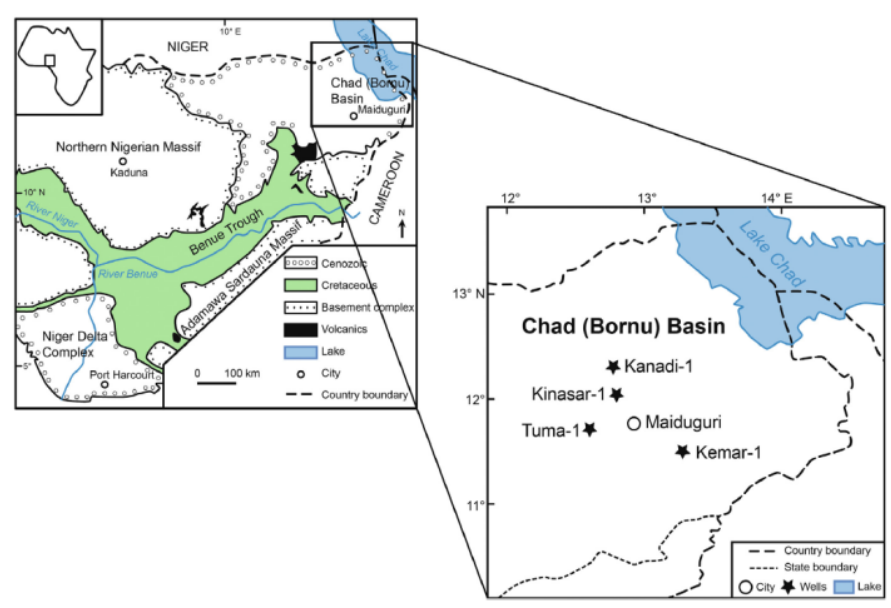

Figure 2: Map of Nigeria showing Bornu-Chad Basin [40].

\subsection{Materials and Methods}

\subsection{Data Acquisition and Processing}

The Chad Basin 3D prospect covers approximately 25.5 km² surface area, near-offset of 500-2300m, mid-offset 2500-4300m, and far-offset of 4500-6300m. An orthogonal cross-spread configuration was adopted for the survey. The survey template consists of 6 receiver lines at 120 shots per salvo and a source and receiver azimuth of $10^{\circ}$ and $100^{\circ}$ respectively. The source/receiver geometry generated full-fold coverage of seventy two (72). The data set was acquired using a dual source of dynamite and vibroseis. Rigorous processing algorithms was applied to correct for statics, remove powerline, ground roll and other random noise.

\subsubsection{Multiple Detection and Attenuation by Predictive Deconvolution}

Multiple Prediction and attenuation method [41,42] based on the Weiner-Levenson method was applied to this data set to predict and attenuate mainly short period multiples and as well collapse reverberation trains in the T-X domain. Prior to application of predictive deconvolution, suitable suites of noise attenuation algorithm were applied on this data to improve the signal-to-noise-ratio. Series of tests were carried out to ensure optimal result. Prediction lag (ms), window length (ms) and pre-whitening (\%) were tested.

\subsubsection{Multiple Detection and Attenuation by Radon Transformation}

Weighted Least Squares Radon transform [43, 44, 45, 46] seeks to improve the focusing of events in the Radon domain over that provided by conventional transforms. This improved resolution is achieved by including prior information about desirable characteristics of the model into the transform. The prior information was in the form of weights in the model domain, chosen to improve trace sparseness of the model whilst still modelling all of the data. Improved focusing in the Radon domain improves identification and separation of signal and noise trends, with reduced artifact levels.

The transform used the parabolic or pseudo-hyperbolic moveout functions the Radon domain to move the mute closer to the primary events. This allowed separation of primary and multiple events with very little moveout discrimination. Radon Multiple Attenuation is principally a subtraction process [47,48]. Unwanted coherent noise was isolated in the tau-p domain, inverse transformed to the $\mathrm{x}$-t domain, and then subtracted from the original data. Multiple energy was then isolated in the tau-p domain because events with different velocities mapped to different parts of the domain. Parameters for the Radon processing is as shown in Table 1. Moveout used in making intermediate p-traces were linearly interpolated between the minimum and maximum moveout

Table 1: Radon Parameters

\begin{tabular}{ll}
\hline Parameters & Values \\
\hline Reference Offset & $6000 \mathrm{~m}$ \\
Window Moveout & Parabolic \\
Multiple Velocity $\left(\mathrm{V}_{\mathrm{m}}\right)$ & $90 \%$ of the primary velocity field \\
& \\
$\begin{array}{l}\text { Number of p-traces } \\
\text { generated }\end{array}$ & 250 \\
$\begin{array}{l}\text { Minimum moveout } \\
\text { (i.e. for the first p- }\end{array}$ & $-300 \mathrm{~ms}$ \\
trace) & \\
$\begin{array}{l}\text { Maximum moveout } \\
\text { (i.e. for the last p- }\end{array}$ & \\
trace) & \\
Velocity field used for & PSTM 1kmx1km smoothed velocity field \\
NMO correction & \\
Signal Protection & \\
Definition: & Min. Moveout (ms);Max. Moveout (ms) \\
Time (ms) & -300 \\
0 & -300 \\
8000 & \\
\hline
\end{tabular}

\subsubsection{Multiple Detection and Attenuation by Extended Internal Multiple Prediction (XIMP)}

XIMP predicted internal multiples using horizon-based approach or layer-based approach picking any horizon. The horizon-based method [23, 49, 50] detects internal multiples related to one or more specific generator horizons at a time and the picked generating horizon times are required to be available as input to this Seismic Processing Module (SPM). The layer-based method does not require any generator horizon to be picked and it predicted internal 
multiples for user-defined generator zone. In SMP mode, XIMP predicted surface-related multiples by using the generating horizon at free surface without requirement for user-supplied horizon times.

The objective of deploying XIMP was to detect interbed multiples from strong multiple generating horizons or layers on the 3D Chad basin dataset. Steps used to run XIMP were as follows:

(i) Data preconditioning,

(ii) Horizon layers time mapping of multiple generating surfaces,

(iii) Multiple modelling and finally,

(iv) Adaptively subtract the modelled multiple layer from the input seismic dataset,

(v) Pre-processing to attenuate noise and improve signal-to-noise $(\mathrm{S} / \mathrm{N})$ for input shot gathers,

(vi) Apply shallow mute to remove far offset and eliminate noise,

(vii) Apply both refraction and residual statics for correct positioning,

(viii) Remove previously applied NMO correction,

(ix) Remove time function gain and automatic gain control (AGC) from data,

(x) Apply spatial amplitude balancing to input data and

(xi) Remove direct arrivals to ensure good multiple prediction.

Horizon was picked over the entire volume on an unmigrated stack for the horizon-based modelling using Petrel software. This ensured identification of interbed multiple generator interval. The output from this process contains the predicted internal multiple model associated with the picked generator horizon or the surface multiple model if it is running with SMP mode. The adaptive subtraction techniques [2] was then used to subtract the multiple model from the seismic data.

\subsection{Results and Discussion}

\subsection{Multiples Detection and Attenuation}

\subsubsection{Multiples Detection and Attenuation using Predictive Deconvolution}

Predictive deconvolution was tested on the datasets. Various values of deconvolution operator, operator length, deconvolution window, and frequency range were tested. Figures 3a shows dataset without autocorrelation. Figures $3 \mathrm{~b}, 3 \mathrm{c}$ and $3 \mathrm{~d}$ show autocorrelation with different operator lengths and deconvolution windows. The autocorrelation function designed and tested with operator lengths of 120,160 , and 240, and tested with gaps of 4, 8, 16 and 24 .

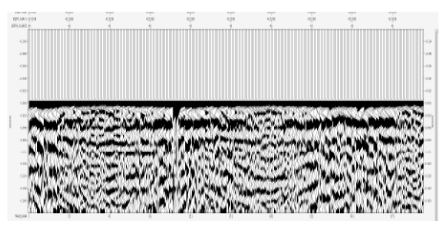

(a)

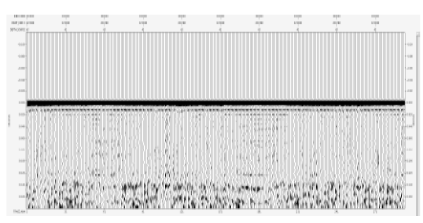

(b)

Figure 3: (a) Pre-Deconvolution Autocorrelation with Automatic Gain Control Applied; (b) Post-Deconvolution Autocorrelation with Operator Length 120 and Gap 4.

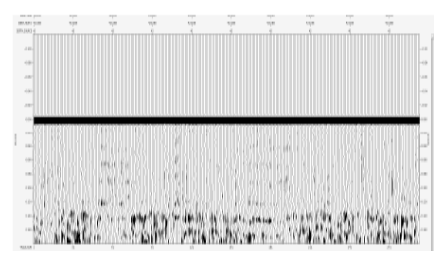

(c)

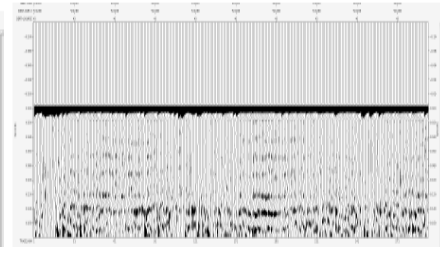

(d)

Figure 3: (c) Post-Deconvolution Autocorrelation with Operator Length 120 and Gap 8; (d) Post-Deconvolution Autocorrelation with Operator Length 120 and Gap 16.

Figure 4 show spectral analysis for various Gaps and Operator Lengths. The test results show significant improvement. Predictive deconvolution differentiated the raw data masked with multiples into primaries and multiples, and attenuated the multiple reflections and alters the spectrum of the input data to increase resolution. Raw CMP data showing pre and post deconvolution stacks are presented in Figures $5 \mathrm{a}$ and Figure $5 \mathrm{~b}$ while Figure $5 \mathrm{c}$ is the multiples and other noises removed from the dataset. It is very clear from the spectrum that whilst deconvolution broadens the spectrum of the input seismic data by collapsing reverberations, the spectrum of the multiple energy attenuated was also broadened prior to being collapsed during the process leaving only the true primary energy with a lower amplitude value post deconvolution (Figure 6).

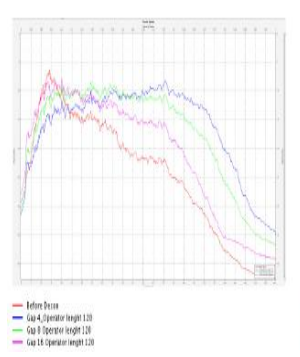

(a)

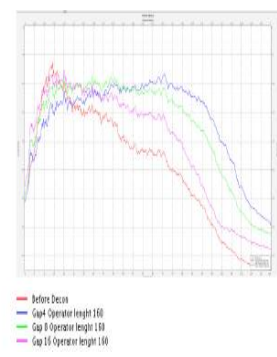

(b)

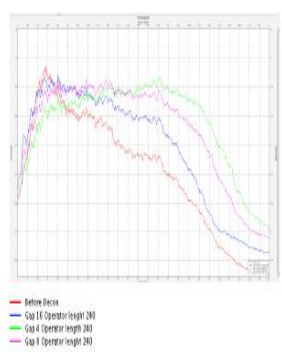

(c) 
Figure 4: (a) Spectral analysis: for Gap 4,8 \& 16ms Operator Length 120; (b) Spectral analysis: for Gap 4, 8 \& 16ms Operator Length 160; (c) Spectral analysis: for Gap 4,8 \& $16 \mathrm{~ms}$ Operator Length 240.

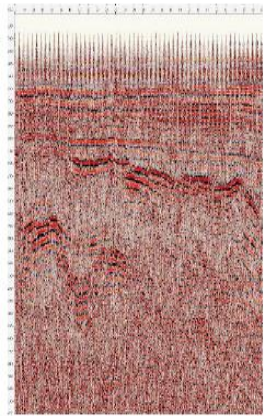

(a)

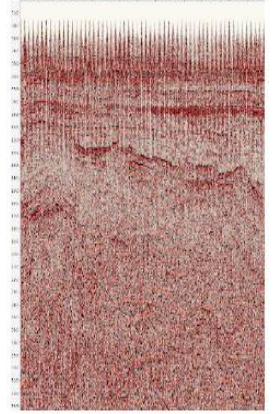

(b)

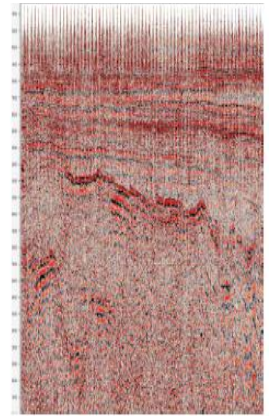

(c)

Figure 5: (a) Inline 20885 before Deconvolution; (b) Inline 20885 after Deconvolution; (c) Inline 20885 Difference - showing

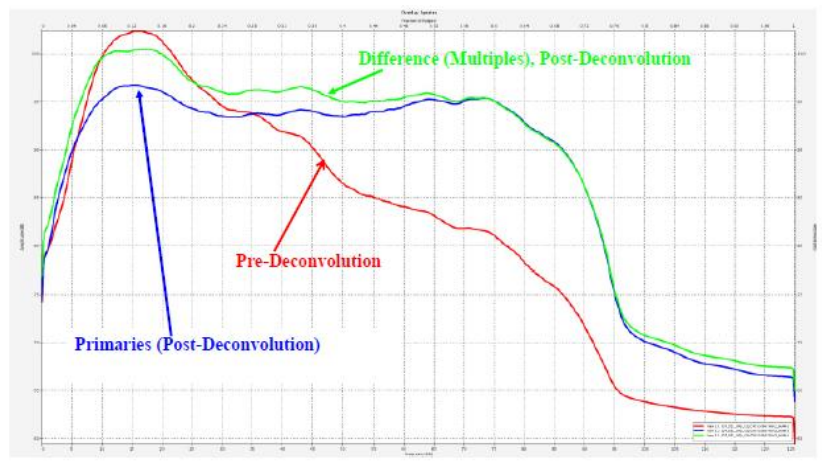

Figure 6: Spectral analysis showing pre- and post deconvolution with difference (multiples).

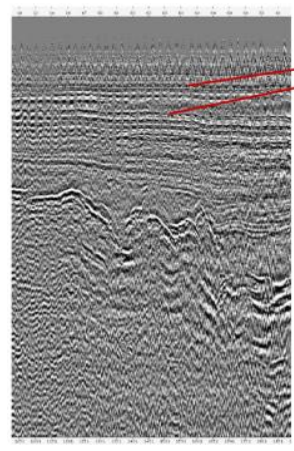

(a)

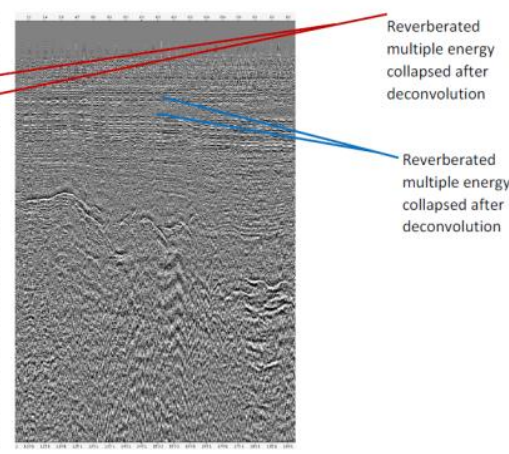

(b)

Figure 7: (a) Inline 20885 showing datasets masked by reverberated multiple energy; (b) showing Inline 20885 with multiple reverberations attenuated.

\subsubsection{Multiples Detection and Attenuation by High Resolution Radon and Velocity Discrimination}

Figure 8 is $1 \mathrm{~km} \times 1 \mathrm{~km}$ velocity panel before Radon was applied to the migrated common mid-point (CMP) gathers. In order to have a true representation of the subsurface velocity, the velocity was picked on migrated gathers. The CMPs show a strong reflector at about $1.5 \mathrm{~s}$ and series of under-corrected events beyond 1.5s. These under-corrected events are multiples. Multiples events have lower velocities (see semblance of the velocity panel of Figure 8) in comparison with primaries. Multiples deviate from the primary velocity trend. Multiples record longer period than primaries on a given reflector since they have lower velocities than primaries. Thus, seen as under-corrected gathers when primary stacking velocity is applied on CMP gathers containing both primaries and multiples. Difference in normal moveout between primaries and multiples is utilised in removing the under-corrected events (multiples) from the seismic data in the study area. After Radon demultiple is applied to the seismic gathers, the multiple events seen in the semblance and gathers (Figure 9) are removed. Having seen significant improvements in the test line 20885, a full demultiple process was applied to the migrated dataset and compared with migrated volume without demultiple. It was clear that the data with full demultiple processess presented a cleaer representation of the geology with well defined faults. The result of additional test lines are here presented along with the time slices.

The spectral analysis (Figure 10) confirms that amplitude of multiples is slightly higher than those of primaries. Figures 11a and 11b are stack sections shows impact of attenuating long wavelength multiples from the Chad Basin with the application of high-resolution radon demultiple. Figure 11a is the dataset without application of radon while Figure $11 \mathrm{~b}$ is the primaries alone with multiples removed. The multiple free data is a better representation of geology. Figure 11c is the removed multiples. 


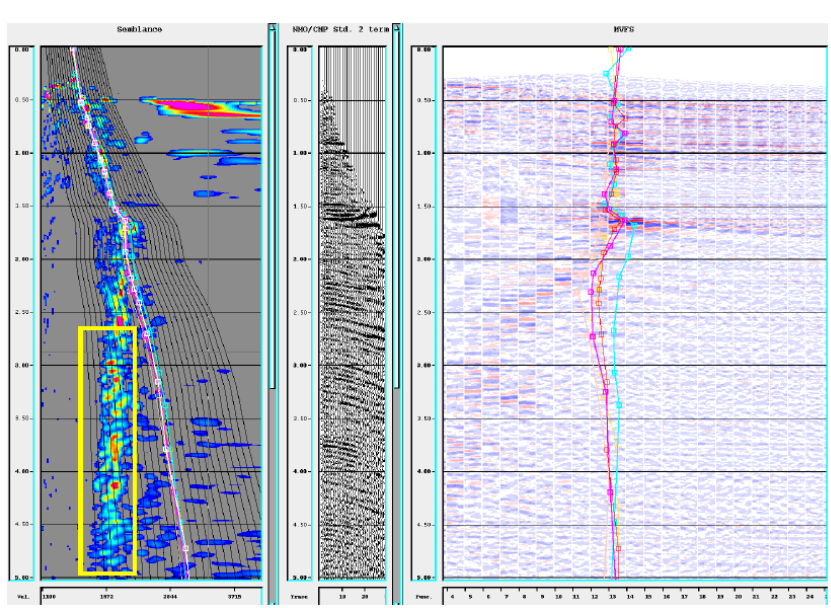

Figure 8: Velocity analysis panel of line 20885 with Radon applied to predict multiples. Multiples stacked out on lower velocities.
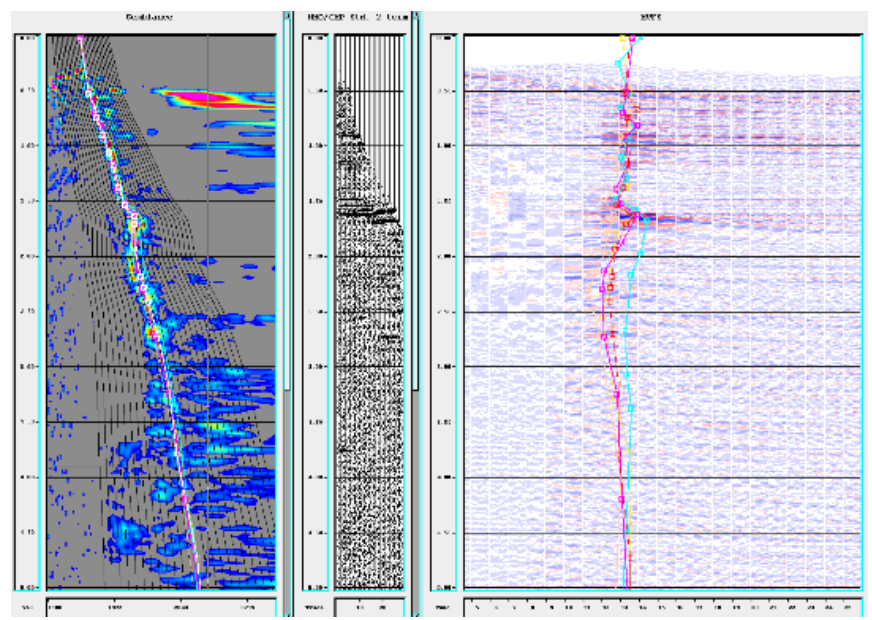

Figure 9: Velocity analysis panel of line 20885 with Predicted Multiples Attenuated after the application of Radon.

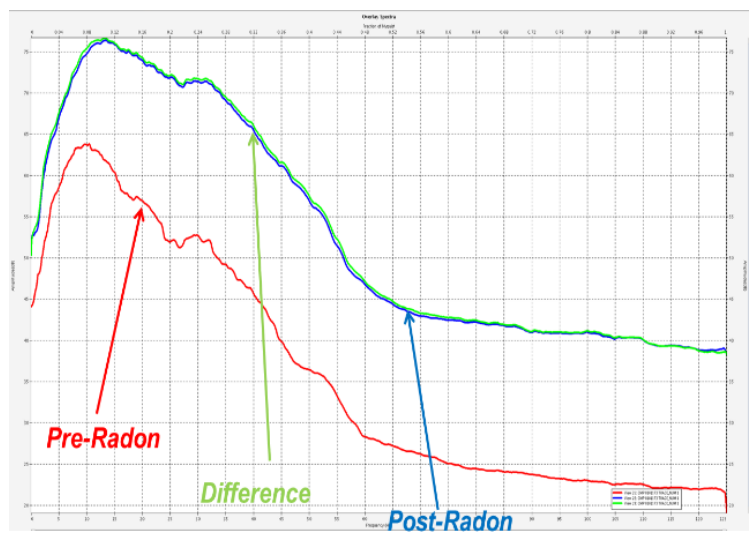

Figure 10: Amplitude Spectra showing Primaries and Multiples with and without Radon demultiple.

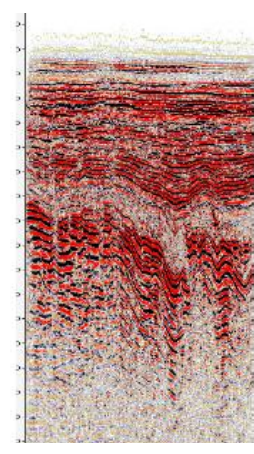

(a)

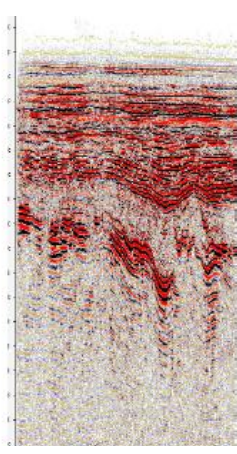

(b)

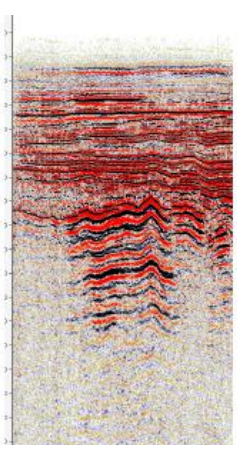

(c)

Figure 11: (a) Inline 20885 dataset masked by long period Multiples; (b) dataset with multiples attenuated after application of Radon demultiple; (c) Inline 20885 Post-Radon Demultiple Difference (Multiples). 


\subsubsection{Multiples Detection by Extended Interbed Multiple Prediction (XIMP)}

Extended internal multiple prediction (XIMP) is a data-driven demultiple algorithm that attenuates interbed multiples. Interbed multiples appear similar to the primaries because of their comparable velocities. They are therefore difficult to differentiate, especially in areas with relatively flat geology. XIMP handled this problem by generating a true azimuth interbed multiple model that was removed using adaptive subtraction techniques. XIMP was able to handle the Chad basin acquisition geometry and predicted multiples at true azimuth was applied after techniques, the result was a much better representation of the primary energy. Figures $12 \mathrm{a}$ and $12 \mathrm{~b}$ show the effect of attenuating interbed multiples on shot gathers. Figures $13 \mathrm{a}$ and $13 \mathrm{~b}$ are stack displays of XIMP application on stacked section. This was performed post migration as the velocities of the primary energy are now a reflection of the subsurface geology. Figure 18 is a display of spectral analysis of both datasets with and without XIMP application. Amplitude of the data with multiple was slightly higher than the dataset with multiples removed.

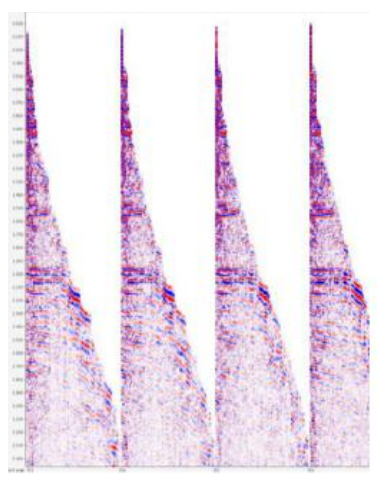

(a)

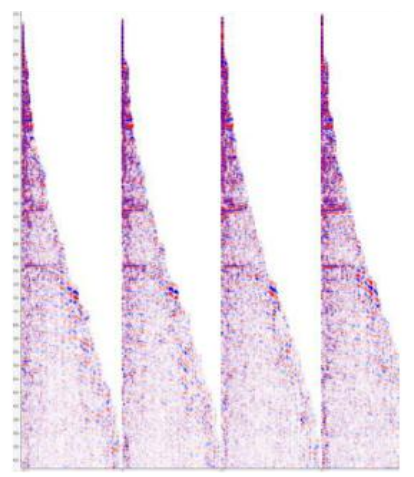

(b)

Figure 12: (a) Inline 20880 Raw Shots Record with Extended Interbed Multiple Prediction (XIMP); (b) Inline 20880 Shot Record without Extended Interbed Multiple Prediction (XIMP).

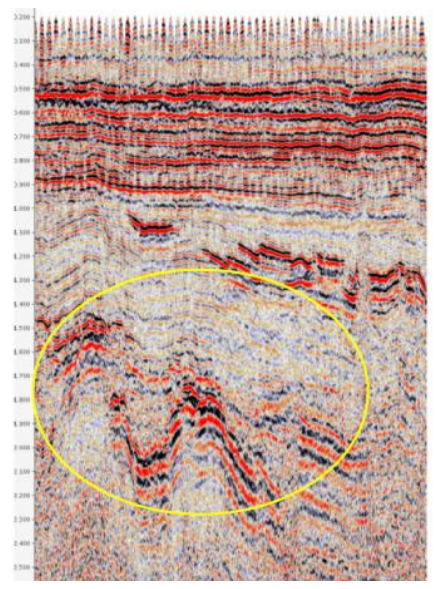

(a)

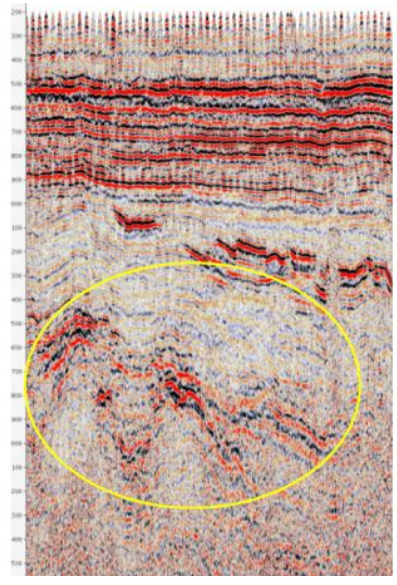

(b)

Figure 13: Inline 20880 stacks showing data before (a) and after (b) XIMP multiple prediction and attenuation.

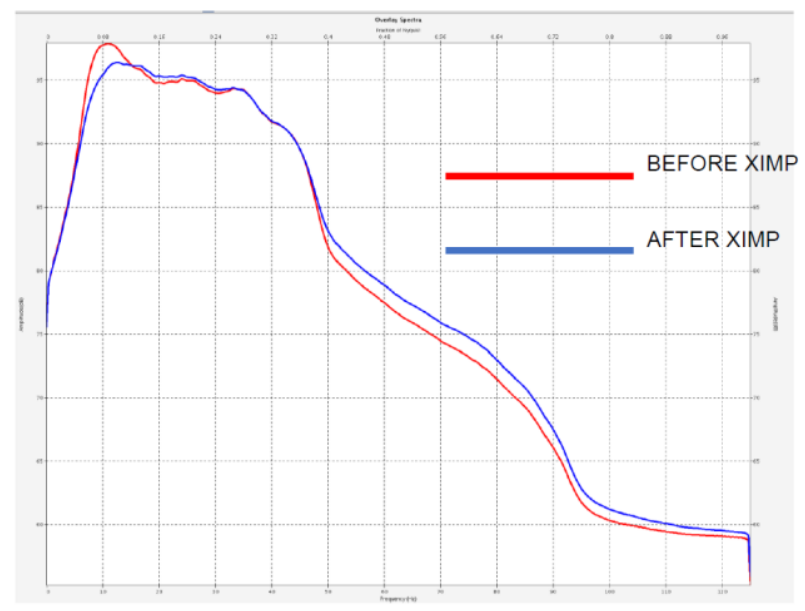

Figure 14: Inline 20880 Extended Interbed Multiple Prediction (XIMP) Spectral Window on stack.

\subsubsection{Spectral Analysis of Primaries and Multiples}

Amplitude and frequency response for the data sets are as shown in Figures 10 and 14. The trend indicates that the processing preserved true amplitudes as there were no change in the spectrum. It is very clear from the spectrum that whilst deconvolution broadens the spectrum of the input seismic data by 
collapsing reverberations. The spectrum of the multiple energy attenuated is also broadened prior to being collapsed. During the process, the true primary energy is left with a lower amplitude value.

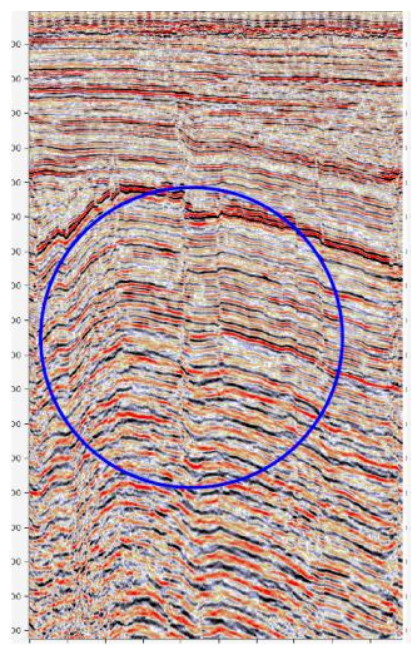

(a)

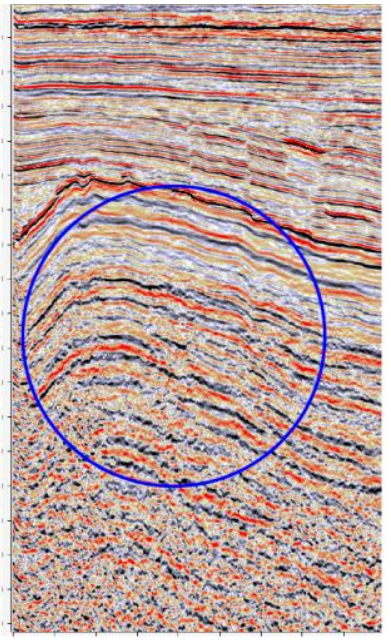

(b)

Figure 15: Inline 20890 Migrated Stack Comparison: (a) data without application of demultiple processes; (b) data with all demultiple processes applied.

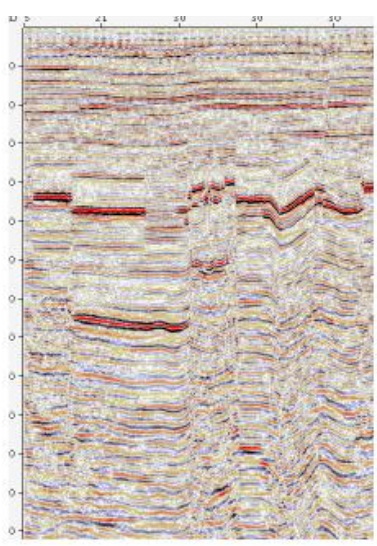

(a)

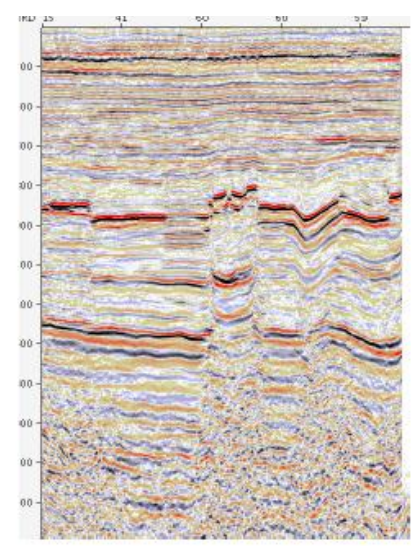

(b)

Figure 16: Inline 20895 Migrated Stack Comparison: (a) data without application of demultiple processes; (b) data with all demultiple processes applied.

\subsection{Signal-to-Noise Ratio before and after Demultiple}

The datasets were completely masked by multiple energy as shown in Figures 11a, 13a, 15a and 16a. Applying appropriate multiple attenuation methods helped to unmask the data from the multiples. Predictive Deconvolution, Radon and XIMP demultiple tools along with velocity discrimination were useful as demultiple techniques for dataset because of the predominant near surface reverbration and interbed multiples (Figures 14b,16b,18b and 19b).

\subsection{Velocity Response of Primaries and Multiples}

From the velocity analysis spectrum and semblance stack, it was clear that the velocities of multiples were much lower than those of primary events. This is why the multiple energy was easily attenuated when the datasets were stacked with higher velocities.

\subsection{Conclusion}

Multiples were detected using predictive deconvolution, high resolution Radon and XIMP algorithms, and adaptively subtracted from the dataset. All the methods yielded primaries and the multiples. The very fact that the raw data could be separated into primaries and multiples (difference) implies the occurrence, prediction and attenuation of the multiples. Useable frequency in this data is between $20 \mathrm{~Hz}$ and $70 \mathrm{~Hz}$.

\section{Acknowledgements}

The authors are grateful to Nigeria National Petroleum Corporation (NNPC) for supply of data.

\section{References}

[1] C.H. Dix, "The existence of multiple reflections”, Geophysics, Vol. 13, Pp. 49-50, 1948.

[2] D.J. Verschuur, A.J. Berkhout, and C.P.A. Wapenaar, “Adaptive surface-related multiple elimination”, Geophysics, Vol. 57, Pp. 1166-1177, 1992.

[3] A.B. Weglein, F.A. Carvalho, and P.M. Stolt, "An inverse scattering series method for attenuating multiples in seismic reflection data", Geophysics, Vol. 62, Pp. 1975-1989, 1997.

[4] H. Jakubowicz, "Wave equation prediction and removal of interbed multiples", 68th SEG Annual International Meeting, SEG, Expanded Abstracts, Pp. 1527-1530, 1998.

[5] A.J. Berkhout, "Seismic migration: Imaging of acoustic energy by wavefield extrapolation", A Theoretical aspect, 2nd Ed. Elsevier, 1999. 
[6] P.G. Kelamis, and D.J. Verschuur, "Surface-related multiple elimination on land seismic data -Strategies via case studies", Geophysics, Vol. 65, Pp. 719734,2000

[7] E. Erez, and L. Ikelle, "The concept of virtual events: Attenuation of internal multiples", 75th SEG Annual International Meeting, SEG, Expanded Abstracts, Pp. 2714- 2716, 2005.

[8] A. Pica, G. Poulain, B. David, M. Magesan, S. Baldock, T. Weisser, P. Hugonnet, and P. Herrmann, "3D surface-related multiple modeling, principles and results", 75th Annual International Meeting, SEG, Expanded Abstracts, Pp. 2080-2083, 2005.

[9] A. Pica, and L. Delmas, "Wave equation based internal multiple modeling in 3D", 78th SEG Annual International Meeting, SEG, Expanded Abstracts, Pp. 2476-2480, 2008.

[10] A. Baumstein, D.L. Hinkley, K.D. Andersen, and T.G. Farrington, "Attenuating diffracted multiples with 3D SRME - A feasibility study", 68th Annual Conference and Exhibition, EAGE, Extended Abstracts, F021, 2006.

[11] K.H. Matson, and G. Xia, "Multiple attenuation methods for wide azimuth marine seismic data", 77th Annual International Meeting, SEG, Expanded Abstracts, Pp. 2476-2479, 2007.

[12] B. Dragoset, I. Moore, M. Yu, and W. Zhao, “3D general surface multiple prediction: An algorithm for all surveys”, 78th SEG Annual International Meeting, SEG, Expanded Abstracts, 2426-2330, 2008.

[13] D.B. Umoetok, "Land multiples prediction and attenuation in Bornu-Chad Basin, Nigeria", Unpublished PhD Thesis, Rivers State University, Port Harcourt, Nigeria, 2019.

[14] B. Gutenberg, and C.Y. Fu, “Remarks on multiple reflections”, Geophysics, Vol. 13, Pp. 45 - 48, 1948.

[15] J.C. Waterman, “Multiple-reflection evidence”, Geophysics, Vol. 13, Pp. 41-44, 1948.

[16] K.E. Burg, M. Ewing, F. Press, and E.J. Stulken, “A seismic wave guide phenomenon”, Geophysics, Vol. 16, Pp. 594-612, 1951.

[17] R.F. Hansen, and C.H. Johnson, "Multiple reflections of seismic energy", Geophysics, Vol. 13, Pp. 58 - 85, 1948.

[18] D. Hampson, "Inverse velocity stacking for multiple elimination", Journal of Canadian Society of Exploration Geophysics, Vol. 22, Pp. 44 - 55, 1986.

[19] J. Wang, and S. Wang, "Practical implementation of SRME for land multiple attenuation", GeoConvention, Calgary, Expanded Abstracts, 2013a.

[20] W. Keith, B. Richard, and G. Ken, “Predicting Free Surface Multiples without the water: SRME on Land”, GeoConvention, FOCUS, Pp. 1 -7, 2014.

[21] A. George-Best, "Multiple Generators in Onshore Niger Delta", International Journal of Scientific \& Engineering Research, Vol. 7 (10), Pp. 368 - 372 , 2016.

[22] A.B. Weglein, "How can the inverse-scattering method really predict and subtract all multiples from a multidimensional earth with absolutely no subsurface information", The Leading Edge, Vol. 18, Pp. 132-136, 1999.

[23] G.A. Meles, K. Löer, M. Ravasi, A. Curtis, C.A.C. Carlos Alberto da Costa Filho, "Internal multiple prediction and removal using Marchenko autofocusing and seismic interferometry", Geophysics, Vol. 80, No. 1, A7-A11, 2015.

[24] 0. Yilmaz, "Seismic data processing. Investigations in Geophysics, vol. 2. Tulsa: Society of Exploration Geophysicists", Society of Exploration Geophysicists, Tulsa, 1987.

[25] I. Trinks, "Removing multiples from the wide-angle wavefield". Lithos Science report, Pp. 113 - 116. 2000.

[26] Y. Yan, "Suppression of water-column multiples by combining components of ocean-bottom seismic surveys", MSc Thesis. University of Calgary, 2002.

[27] Y. Wang, "Multiple prediction through inversion: a fully data-driven concept for surface-related multiple attenuation", Geophysics, Vol. 69, Pp. 547$553,2004$.

[28] D.C. Riley, and J.F. Claerbout, “2-D multiple reflections”, Geophysics, Vol. 41, Pp. 592-620, 1976.

[29] D. Lokshtanov, "Suppression of water-layer multiples -from deconvolution to wave-equation approach”, SEG Expanded Abstracts, Pp. 1981 - 1984 , 2000 .

[30] C. Xiao, J. Bancroft, J. Brown, and Z. Cao, “Multiple suppression”, A literature review: Crewes Report, 15, 2003.

[31] B.L.N. Kennett, "The suppression of surface multiples on seismic records", Geophysical Prospecting, Vol. 27, no. 3, pp. 584-600, 1979.

[32] I.F. Jones, and S. Levy, "Signal-to-noise ratio enhancement in multichannel seismic data via the Karhunen-Loève transform”, Geophysical Prospecting, Vol. 35, Pp. 12 - 32, 1987.

[33] G.F. Margrave, "The methods of seismic data processing”, Department of Geology and Geophysics, University of Calgary, 1999.

[34] D.B. Umoetok, and E.D. Uko, "Characteristics of multiples in shallow and deep marine seismograms in Gulf of Guinea", Petroleum Technology Development Journal, Vol. 5 no. 2, Pp. 72 - 83, 2015.

[35] D.O. Ogagarue, and J.O. Ebeniro, "An Improved Dual Sensor Summation Method with Application to Four-component (4-C) Seafloor Seismic Data from the Niger Delta”, Earth Science Research, Vol. 4, no. 2, Pp. 172-177, 2015.

[36] D.O. Ogagarue, and C.N. Nwankwo, "A Statistical Amplitude Analysis Method with Application to Streamer Data from the Niger Delta Offshore", Journal of Applied Geology and Geophysics, Vol. 4, no. 2, Pp. 10-14, 2016.

[37] N.G. Obaje, M.K., Musa, A.N. Odoma, and A. Hamza, "The Bida Basin in North-Central Nigeria: Sedimentology and Petroleum geology", Journal of Petroleum and Gas Explo. Research, Vol. 1, No. 1, Pp. 001-013, 2011.

[38] A.A. Adepelumi, O.A. Alao, and T.F. Kutemi, "Reservoir characterization and evaluation of depositional trend of the Gombe sandstone, southern Chad basin Nigeria", Journal of Petroleum and Gas Engineering, Vol. 2, no. 6, Pp. 118-131, 2011. 
[39] G.J. Genik, "Regional Framework Structure and petroleum aspects of the rift basins in Niger, Chad and Central African Republic (C.A.R.)", Tectonophysics, Vol. 213, Pp. 169-185, 1992.

[40] A.O. Ola-Buraimo, and Y. Abdulganiyu, "Palynology and stratigraphy of the Upper Miocene Chad Formation, Bornu Basin, northeastern Nigeria", Journal of Palaeogeography, Vol. 6, no. 2, Pp. 108-116, 2017.

[41] B. Gibson, and K. Larner, "Predictive deconvolution and the zero-phase source”, Geophysics, Vol. 49, Pp. 379-397, 1984.

[42] F. Kircheimer, “3-D Refraction statics by weighted least-squares inversion: 59th Ann. Internat”, Mtg., Soc. Expl. Geophys., Expanded Abstracts, Pp. 794$797,1988$.

[43] J. Sun, and K.A. Innanen, “1.5D Internal multiple prediction in the plane wave Domain”, CSEG Expanded Abstracts, 2015.

[44] J. Sun, and K.A. Innanen, "Interbed multiple prediction on land: Which Technology, and which Domain", CSEG Recorder, Pp. 26-31, 2016.

[45] M. Bekara, A. Ferreira, and M. Vanderbaan, "A statistical technique for high amplitude noise detection: Application to swell noise attenuation", SEG Technical Program Expanded Abstracts, 27, 2008

[46] L.R. Lines, and S. Treitel, "Tutorial: A review of least-squares inversion and its application to geophysical problems", Geophysical Prospecting, Vol. 32, Pp. 159-186, 1984.

[47] J. Guo, "Adaptive multiple subtraction with a pattern-based technique”, 73rd Soc. Expl. Geophys. Ann. Mtg., Expanded Abstracts, Pp. $1953,2003$.

[48] M. Guo, Y. Kim, S. Sen, J. Xu, J. Xie, and B. Wang, "A new multiple subtraction method using the attributes of predicted multiples", 78th SEG Annual International Meeting, SEG, Expanded Abstracts, Pp. 2451-2455, 2008.

[49] Z.J. Wu, and S.B. Dragoset, "Robust internal multiple prediction algorithm”, SEG San. Antonio 2011 Annual Meeting, pp. 3541-3545, 2011.

[50] Umoetok, B. Dorathy, D. Uko, Etim, and P. Ngeri, Aminayanasa, Attenuation of water-bottom multiples: a case study from shallow marine in the Niger Delta, Nigeria. Malaysian Journal of Geosciences, Vol. 3, no. 1, Pp. 61-65, 2019. 